\title{
Graphs and Boxes
}

\section{GRAPHS}

4.1 Adjusted and annual variations in growth rate of total US productivity, 1965-1999

4.2 Comparative changes over two cycles in real wages and productivity

4.3 ICT is primarily used for professional purposes

4.4 Unlike Japanese stocks, US share prices have been tracking the diffusion of ICT

4.5 1996-2000: the evidence of a financial bubble

5.1 The economies that were part of a virtuous circle of growth regime

5.2 Is there any link between the production and the utilization of ICT?

6.1 By 1998 profits were already starting to erode 85

6.2 A capital structure that has become increasingly heavy

8.1 A comparison of trends in household spending on durable goods and on health

9.1 Does belief in a new era herald the advent of a crisis?

\section{$\mathrm{BOX}$}

8.1 Access to information is no substitute for competency and knowledge 